\begin{tabular}{|c|c|c|}
\hline 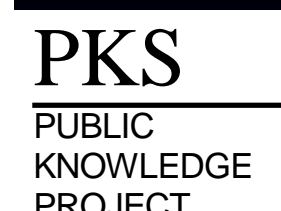 & $\begin{array}{c}\text { REVISTA DE GEOGRAFIA } \\
\text { (RECIFE) } \\
\text { http://www.revista.ufpe.br/revistageografia }\end{array}$ & $\begin{array}{l}\text { OJS } \\
\text { OPEN } \\
\text { JOUNAL } \\
\text { SYSTEMS }\end{array}$ \\
\hline
\end{tabular}

\title{
PARÂMETROS ESTATÍSTICOS NOS SEDIMENTOS DE FUNDO DO COMPLEXO ESTUARINO DE SUAPE - PERNAMBUCO
}

\author{
Luciano Cintrão Barros ${ }^{1}$, Lúcia Maria Mafra Valença ${ }^{2}$, João Adauto Souza Neto ${ }^{3}$ \\ ${ }^{1}$ Universidade Federal do Vale do São Francisco (UNIVASF). Email: luciano.cintrao@univasf.edu.br \\ ${ }^{2}$ Universidade Federal de Pernambuco (UFPE).Email: lmmv@ufpe.br \\ ${ }^{3}$ Universidade Federal de Pernambuco (UFPE). Email: adauto@ufpe.br
}

Artigo recebido em 11/12/2017 e aceito em 09/03/2018

\begin{abstract}
RESUMO
A área de estudo está localizada na região do Complexo Industrial e Portuário de Suape (CIPS) a aproximadamente $40 \mathrm{~km}$ do Recife, entre os municípios do Cabo de Santo Agostinho e Ipojuca, litoral sul de Pernambuco. A presente pesquisa foi dirigida com o objetivo de caracterizar os sedimentos de fundo do Complexo Estuarino de Suape. Foram coletadas e analisadas 111 amostras visando calcular os parâmetros estatísticos para caracterização dos sedimentos. Os resultados indicaram a predominância da fácies areia siliciclástica de granulometria areia média. Os sedimentos apresentaram seleção de pobremente selecionado a muito pobremente selecionado, com assimetria aproximadamente simétrica e distribuições mesocúrticas e leptocúrticas, indicando um elevado nível de energia, em consequência da influência de ondas, marés e correntes fluviais.
\end{abstract}

Palavras-chave: sedimentos de fundo; estuários; Porto de Suape.

\section{STATISTICAL PARAMETERS IN THE BOTTOM SEDIMENTS OF THE SUAPE ESTUARINE COMPLEX - PERNAMBUCO}

\begin{abstract}
The study area is located in the region of Suape Industrial and Port Complex (CIPS) approximately 40km aw ay from Recife, between the municipalities of Cabo de Santo Agostinho and Ipojuca, south coast of Pernambuco. The present research was conducted with the objective of characterizing the bottom sediments of the Suape Estuarine Complex. In total, 111 samples were collected and analyzed aiming to calculate the statistical parameters for sediment characterization. The results indicated the predominance of siliciclastic sand facies of medium sand granulometry. The sediments presented selection from poorly selected to very poorly selected, with nearly symmetrical asymmetry and mesocurtic and leptokurtic distributions, indicating a high level of energy, as a consequence of the influence of waves, tides and fluvial currents.
\end{abstract}

Key-words: bottom sediments; estuaries; Suape Port.

\section{INTRODUÇÃO}

Os estuários são sistemas extremamente resilientes a ação antrópica, regidos pela interação de diversos processos físico-químicos, hidrodinâmicos, morfológicos e biológicos. Apesar de normalmente possuírem grande importância econômica e ecológica devido a sua alta complexidade, estes ecossistemas nem sempre são estudados de forma eficiente. 
A área de estudo está localizada na região do Complexo Industrial e Portuário de Suape (CIPS), litoral sul do estado de Pernambuco, entre o município do Cabo de Santo Agostinho e o Pontal do Cupe (Suape, 2008), distando 40 km da cidade de Recife (Figura 1).

Esta pesquisa tem por objetivo descrever as características dos sedimentos de fundo do Complexo Estuarino de Suape através dos seus parâmetros estatísticos.

Figura 1 - Mapa de localização da área de estudo.

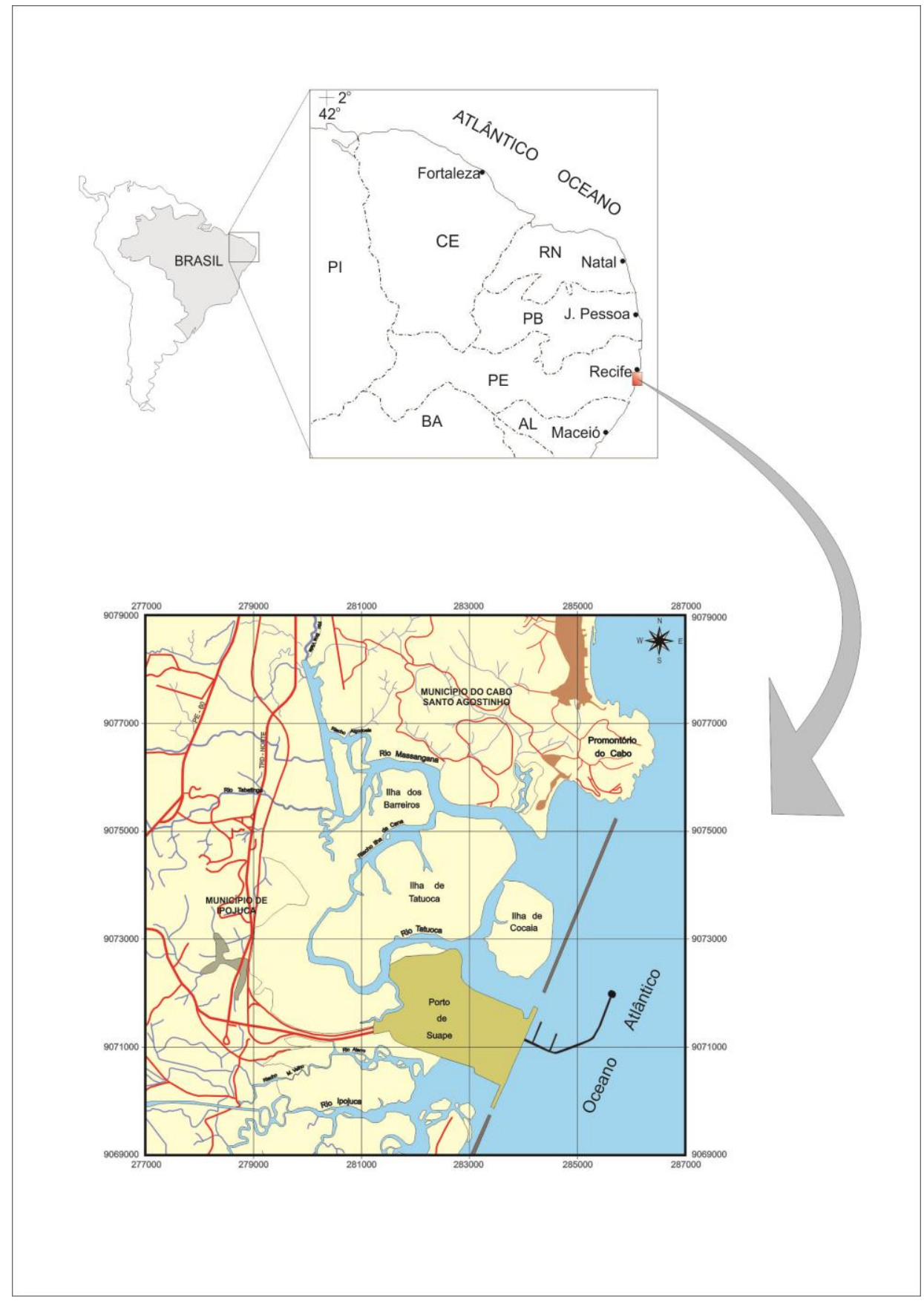




\section{MATERIAL E MÉTODOS}

O levantamento sedimentológico foi realizado nos estuários da região de entorno do porto de Suape: estuários do rio Massangana e Tatuoca e seus tributários, como também a Baía de Suape, onde foram coletadas 111 amostras de sedimentos superficiais de fundo durante três etapas de campo em junho de 2006.

A amostragem foi baseada em perfis transversais ao longo da área de estudo utilizando um amostrador pontual de superfície do tipo Van Veen e posicionada através de um receptor de satélite (GPS modelo Garmin 12). As amostras foram analisadas granulometricamente por peneiramento e técnicas de pipetagem no Laboratório de Sedimentologia da Universidade Federal do Rio Grande do Sul (CECO/UFRGS) no período de outubro a dezembro de 2006.

Os resultados obtidos foram processados pelo Programa de Análise Incompleta da Amostra - PANICOM (Toldo Jr. \& Dorneles, 1991). Após esta etapa foi utilizado o programa Sysgran 3.0 para calcular os parâmetros estatísticos segundo Folk \& Ward (1957).

Posteriormente os dados foram geoferrenciados e interpolados gerando assim os mapas dos parâmetros estatísticos (média, desvio-padrão, assimetria e curtose). A base cartográfica utilizada para a confecção dos referidos mapas foi à Carta de Nucleação Sul da Região Metropolitana do Recife da FIDEM (2002) na escala de 1:20.000.

\section{RESULTADOS E DISCUSSÕES}

Os parâmetros estatísticos refletem os processos de transporte e deposição dos sedimentos, sendo assim de fundamental importância nos estudos de ambientes sedimentares.

\section{Diâmetro Médio}

Os percentuais do diâmetro médio nas amostras indicaram à existência de nove classes texturais na área de estudo, que variaram desde areia grossa a argila grossa, compreendendo a predominância de sedimentos siliciclásticos (Figura 2). Os valores percentuais de areia média a grossa predominaram, compreendendo 50\% das amostras, enquanto que os menores índices foram de silte médio e argila grossa com aproximadamente $3 \%$ cada classe. 
Figura 2 - Valores percentuais do diâmetro médio nas amostras.

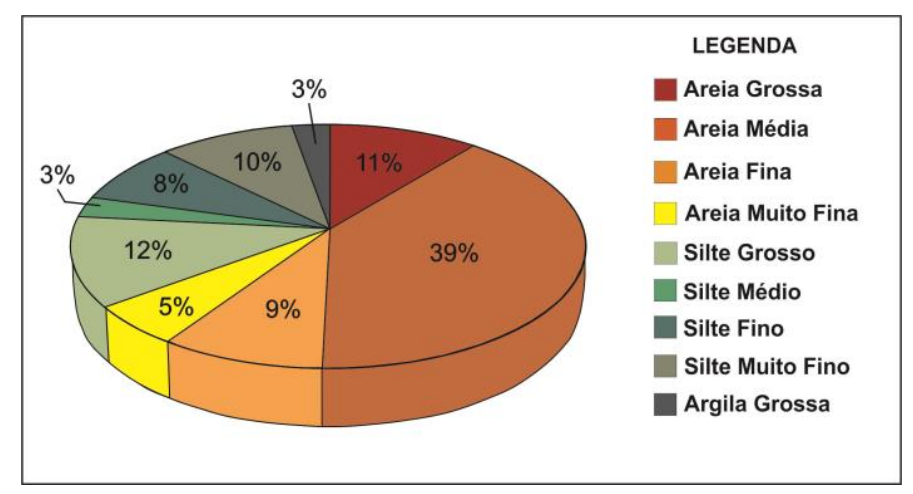

Observou-se que as frações de areia grossa estão localizadas na entrada da Baía de Suape em frente ao promontório do Cabo de Santo Agostinho, estando relacionadas à hidrodinâmica mais intensa principalmente pela ação de ondas e associada à fragmentação do substrato recifal (beachrocks) adjacente (Figura 3).

Foi encontrada também uma quantidade considerável desta fração na porção média do rio Massangana estando em parte relacionados à presença de bioclásticos na região. Verificou-se também uma distribuição pontual em alguns locais dentro da Baía de Suape e no riacho Ilha da Cana.

As areias médias predominam ao norte da Baía de Suape até as imediações da Ilha de Cocaia. São encontrados também em proporções variadas no estuário do rio Massangana. As areias finas a muito finas ocorrem na parte sul da Baía de Suape, nas proximidades da Ilha de Cocaia principalmente na região mais abrigada, onde se verifica a presença de vegetação de mangue. Encontram-se ainda distribuídas ao longo dos estuários dos rios Massangana e Tatuoca, no riacho Ilha da Cana e pontualmente no canal retificado. 
Figura 3 - Mapa de distribuição dos valores de diâmetro médio nos sedimentos superficiais.

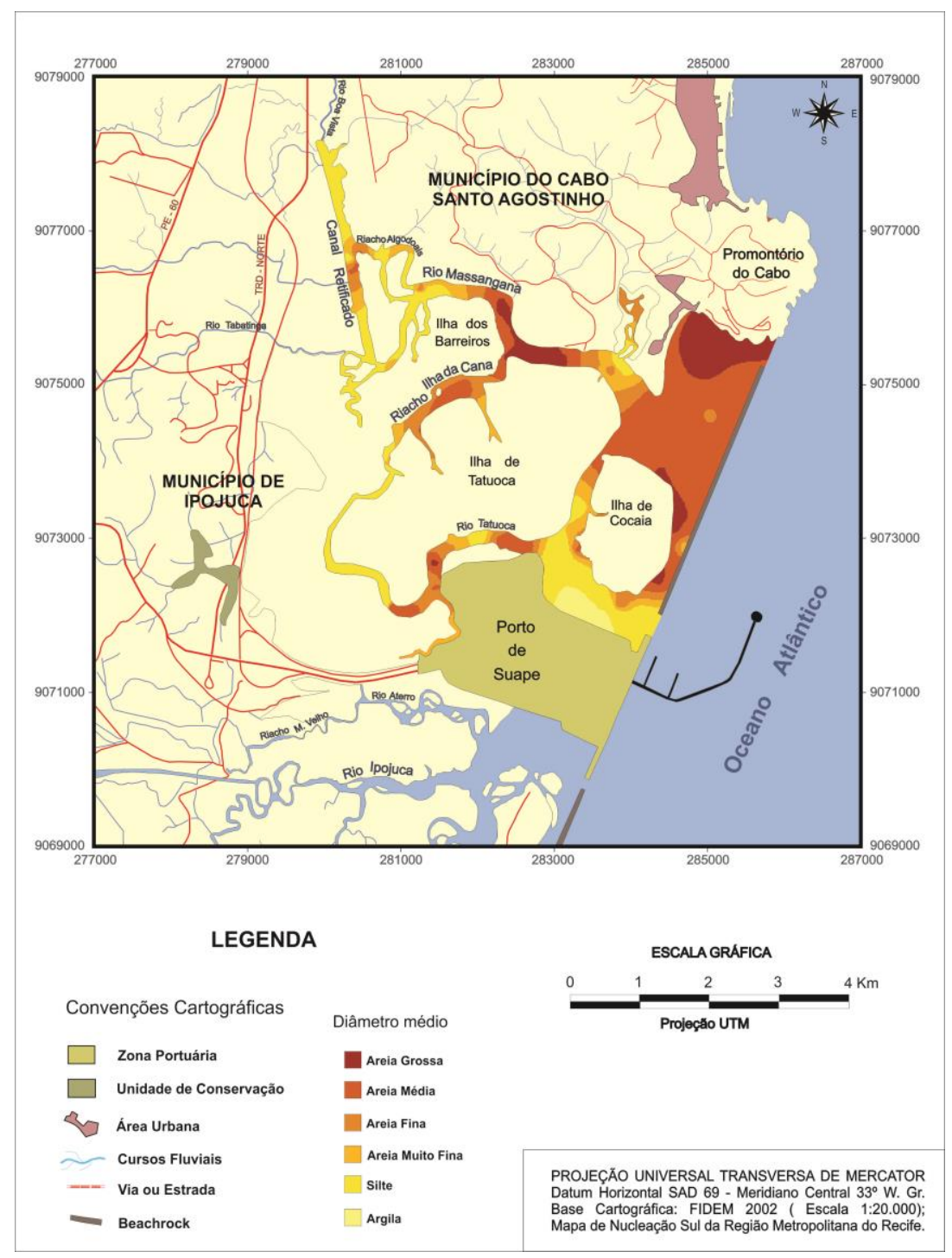

Os sedimentos sílticos distribuem-se formando uma grande mancha em frente ao porto de Suape. Ocorrem de forma mais pontual nos trechos superior e inferior do estuário do rio Massangana e na confluência do estuário do rio Tatuoca com o riacho Ilha da Cana. Sua presença foi observada também nos mangues localizados na parte inferior do estuário do rio Massangana. Predominam também no canal retificado e confluência. A fração mais argilosa forma um grande bolsão no setor interno do cais do porto de Suape, num ambiente historicamente marcado por constantes dragagens. O predomínio de partículas sedimentares maiores aponta um fluxo hidrodinâmico bem intenso nos estuários. 


\section{Desvio Padrão}

Os valores percentuais do desvio padrão nas amostras analisadas da área de estudo, apresentaram a maior predominância das classes pobremente a muito pobremente selecionados com $68 \%$ do total, seguidos da categoria moderadamente selecionada com $31 \%$ e bem selecionada com pouca representatividade, apenas $1 \%$ (Figura 4).

Figura 4 - Valores percentuais do desvio padrão nas amostras.

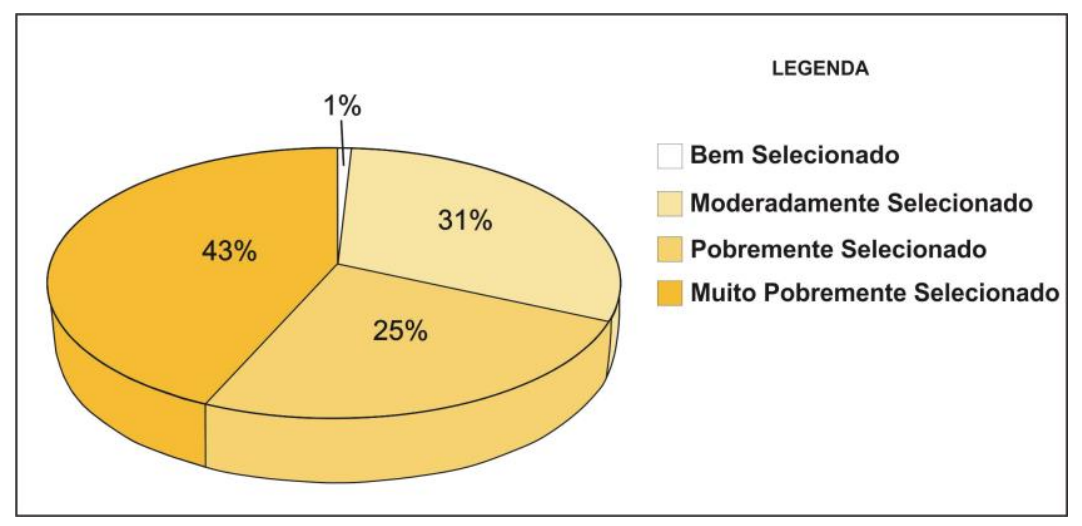

Sua distribuição mostrou que os sedimentos pobremente a muito pobremente selecionados predominam em toda área de estudo (Figura 5). Os sedimentos pobremente selecionados estão presentes em toda parte norte da Baía de Suape com algumas manchas nas proximidades da ilha de Cocaia, nos setores superior e inferior do estuário do rio Massangana, em quase toda a extensão do riacho da Ilha da Cana e também nos setores médio e inferior do estuário do rio Tatuoca.

Os sedimentos muito pobremente selecionados estão localizados na área de influência do porto de Suape estendendo-se até a parte interna da ilha de Cocaia e também nas regiões mais distais tanto do rio Tatuoca quanto do rio Massangana.

Os sedimentos moderadamente selecionados estão distribuídos no setor médio da baia de Suape e também uma mancha no setor médio do rio Massangana. Outras ocorrências são verificadas no rio Tatuoca e no riacho da Ilha da Cana. Os resultados indicam influencia tanto fluvial como marinha com diferentes tamanhos de grãos. 
Figura 5 - Mapa de distribuição dos valores de desvio padrão nos sedimentos superficiais.

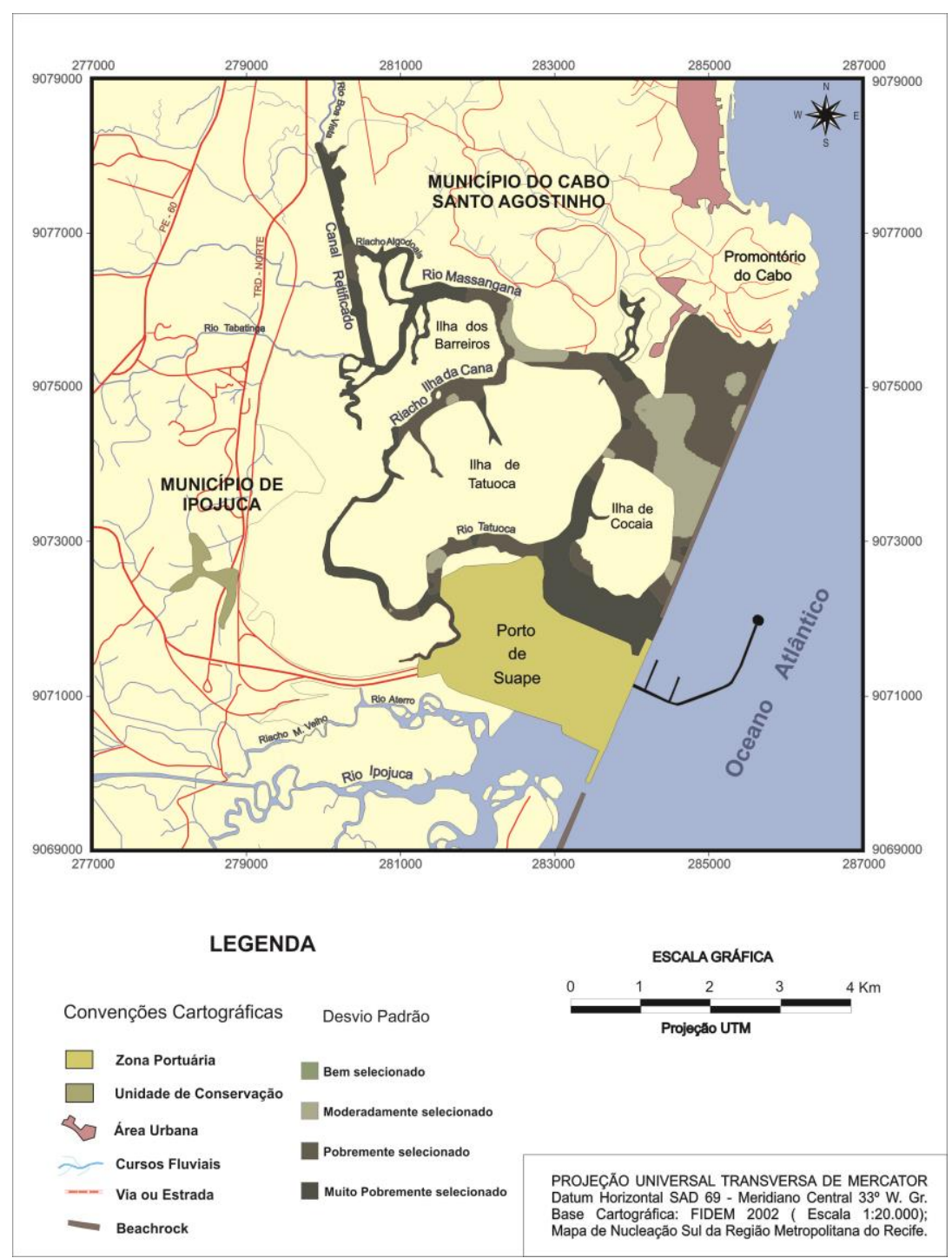

\section{Assimetria}

Diversos autores consideram a assimetria como sendo o parâmetro granulométrico mais sensível para caracterizar um ambiente, principalmente com relação ao nível energético do mesmo.

De acordo com a figura abaixo (Figura 6) as amostras apresentaram valores percentuais de assimetria variando entre positiva a muito positiva (43\%), seguidos de aproximadamente simétrica $(36 \%)$ e negativa $(21 \%)$. 
Figura 6 - Valores percentuais de assimetria nas amostras.

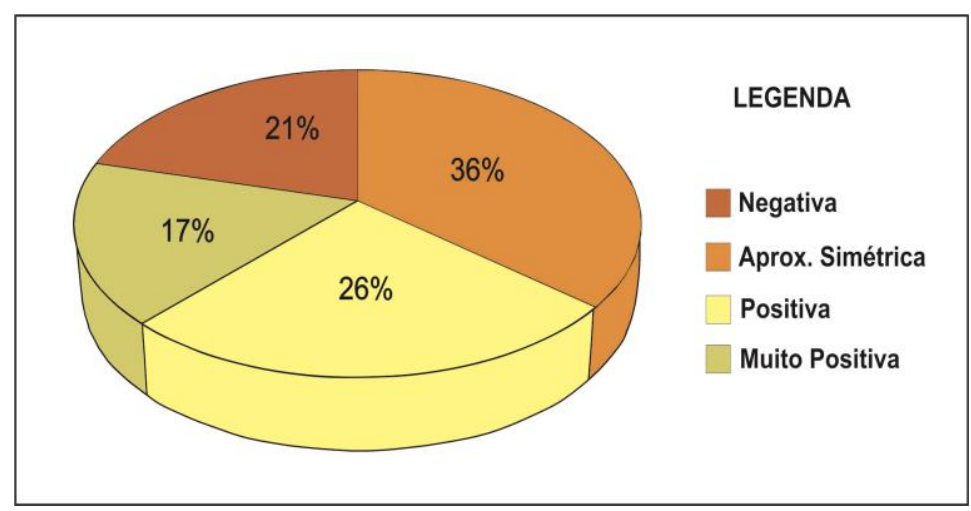

A distribuição dos valores na área de estudo revelou que assimetria positiva a muito positiva dominam principalmente nas proximidades da Ilha de Cocaia, no setor inferior do estuário do rio Massangana, no trecho do Riacho Algodoais e na maior parte do canal retificado (Figura 7).

Ocorre também em vários trechos tanto no riacho da Ilha da Cana quanto no estuário do rio Tatuoca. Esses percentuais demostram a influência de partículas mais finas de sedimentos.

Os valores aproximadamente simétricos distribuem-se no setor norte e sul da Baía de Suape e na porção oeste da ilha de Cocaia. Dominam no trecho superior e médio do estuário do rio Massangana, na maior parte do riacho da Cana e diversos trechos do Tatuoca.

Os valores de distribuição de assimetria negativa dominam principalmente em três locais da área estudada: no setor norte da baia de Suape (promontório do Cabo), no setor sul da baia de Suape, em frente ao terminal do porto de Suape e também na interseção entre o riacho da Cana e o rio Tatuoca. Esses valores denotam uma tendência para as frações mais grossas, podendo estar relacionado ao revolvimento dos materiais pelas atividades de dragagens comuns nesta região. 
Figura 7 - Mapa de distribuição dos valores de assimetria nos sedimentos superficiais.

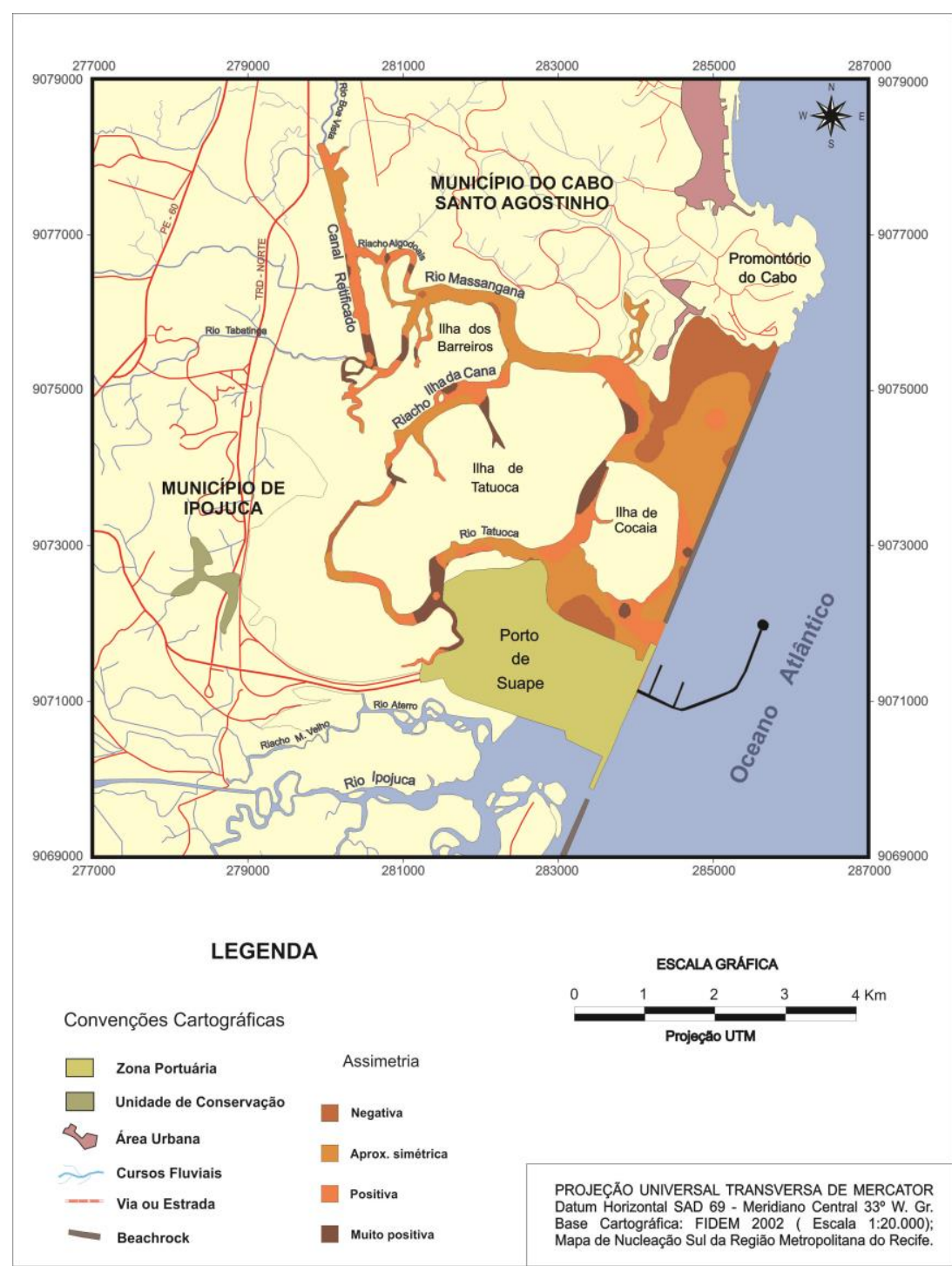

\section{Curtose}

Os sedimentos analisados apresentaram um equilíbrio entre os percentuais leptocúrticas a muito leptocúrticas (36\%) e mesocúrticos (33\%), enquanto as platicúrticas a muito platicúrticas representam 31\% (Figura 8). 
Figura 8 - Valores percentuais de curtose nas amostras.

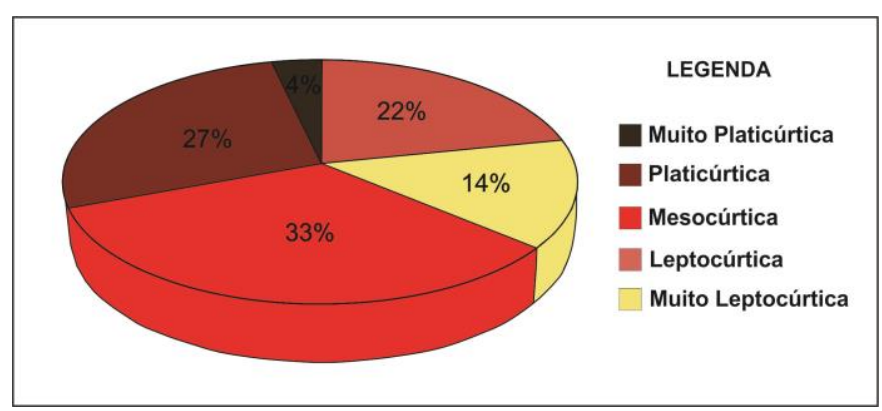

A distribuição revelou que a ocorrência de curtose leptocúrticas a muito leptocúrticas de maneira expressiva no setor médio da Baia de Suape, ao sul da Ilha de Cocaia e setores superior e inferior do Massangana (Figura 9). Localmente foram observados também nos riachos Algodoais e Ilha da Cana, no canal retificado, setores médio e inferior do Tatuoca.

Figura 9 - Mapa de distribuição dos valores de curtose nos sedimentos superficiais.

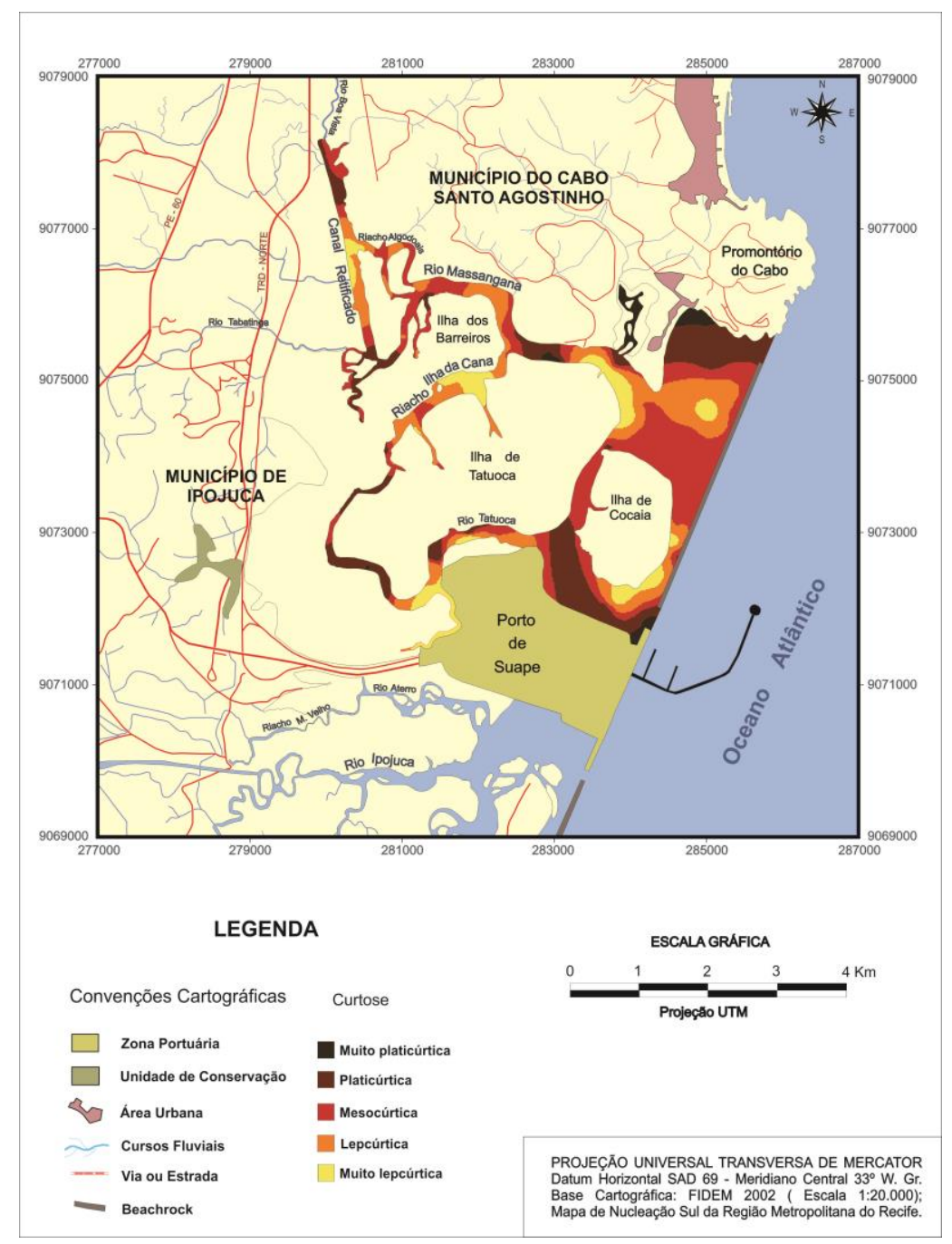


Os sedimentos mesocúrticos encontram-se na porção média da Baía de Suape e também no setor leste-oeste da Ilha de Cocaia. Verificam- se manchas de diferentes tamanhos em todos os estuários da região interna de Suape.

Os sedimentos platicúrticos a muito platicúrticos representam pouca relevância na área, distribuindo-se principalmente nos setores mais extremos da Baía de Suape, tanto ao norte (promontório do Cabo) quanto ao sul (zona portuária) onde possivelmente há uma mistura maior entre as populações em função das distintas direções de fluxos atuantes, indicando um elevado nível de energia, em consequência da influência de ondas, marés e correntes fluviais.

\section{CONSIDERAÇÕES FINAIS}

Com relação à sedimentologia foi observada a predominância da fácies areia de origem siliciclástica, principalmente na Baía de Suape, estuário do rio Massangana e riacho Ilha da Cana com predominância do tamanho areia média.

A distribuição dos sedimentos superficiais de fundo na região estuarina adjacente ao Porto de Suape demonstrou claramente que as fácies sedimentares estão dispostas segundo a hidrodinâmica e a profundidade local. A velocidade das correntes nos estuários é elevada principalmente na maré vazante, onde os sedimentos são levados em direção ao mar.

De uma maneira geral a região de estudo possui baixas profundidades, onde os trechos mais profundos não ultrapassam a cota de $4 \mathrm{~m}$, com exceção da Baía de Suape, que pode atingir 16 metros nas proximidades do terminal portuário.

$\mathrm{Na}$ medida em que nos afastamos da Baía de Suape e da desembocadura dos estuários do rio Massangana e Tatuoca, a intensidade das correntes de maré diminui consequentemente, começam a depositar sedimentos finos associados ou não com outras classes sedimentares. Nas porções média e distal dos estuários, verifica-se uma maior mistura de classes texturais, podendo está associada a valores intermediários de correntes hidrodinâmicas.

Recomenda-se realizar medições de direção e velocidade das correntes ao longo de toda área de estudo, visando conhecer melhor o mecanismo de deposição e remoção dos sedimentos estuarinos. 


\section{REFERÊNCIAS}

FIDEM, Carta de Nucleação Sul da Região Metropolitana do Recife. Escala 1:20.000. 2002.

FOLK, R.L. \& WARD, W.C., 1957. Brazos rives bar: A study in the significance of grain size parameters. Journal of Sedimentary Petrology, Tulsa, Okla, 27: 3-27.

SUAPE, Complexo Industrial Portuário. Relatório da Administração. 24p. Acesso em 05.02.2010. Disponível em http://www.suape.com.br. 2008.

TOLDO JR., E.E. \& DORNELES, C.E., 1991. Programa de Análise Incompleta (PANICOM). Sistema de Análises Granulométricas. Instituto de Geociências. Universidade Federal do Rio Grande do Sul (UFRGS). Porto Alegre. 